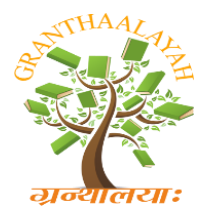

$$
\begin{aligned}
& \text { INTERNATIONAL JOURNAL OF RESEARCH - } \\
& \text { GRANTHAALAYAH } \\
& \text { A knowledge Repository }
\end{aligned}
$$

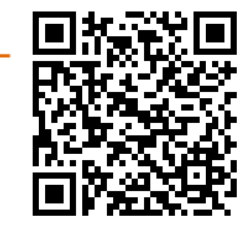

Social

\title{
THE ROLE OF ACADEMIC MOTIVATION AND ACADEMIC SELF CONCEPT IN STUDENT'S ACADEMIC ACHIEVEMENT
}

\author{
M. Kalaivani ${ }^{* 1}$, Dr. V. Rajeswari ${ }^{2}$ \\ ${ }^{* 1}$ PhD Research Scholar, Department of Education, Mother Teresa Women's University \\ Kodaikanal, INDIA \\ ${ }^{2}$ Prof \& Head, Department of Education, Mother Teresa Women's University, Kodaikanal, \\ INDIA
}

DOI: https://doi.org/10.29121/granthaalayah.v4.i9(SE).2016.2508

\begin{abstract}
Education is important to cultivate good values among the public in society. Education helps men to develop their life style. The ultimate goal of school is to educate young people to become responsible. Education is the complete development of individuality of the child so that the man can make an original contribution to human life according to the best of his capacity.. Both academic motivation and academic self-concept promote positive learning environment among the students. It is not just a desire only to achieve but it makes every student to excel in every actions. Proper motivation helps them to do their studies in the best way. Likewise highest self-concept students can easily achieve high in their academics. Both academic motivation and academic self-concept bring out the students' potentialities and make the students to be successful in their academic prospects. Hence this paper attempts to explore the importance of academic motivation and academic self-concept in academic achievement.
\end{abstract}

Keywords:

Motivation, Desire, Psychological, Education, Young People.

Cite This Article: M. Kalaivani, and Dr. V. Rajeswari, "THE ROLE OF ACADEMIC MOTIVATION AND ACADEMIC SELF CONCEPT IN STUDENT'S ACADEMIC ACHIEVEMENT", International Journal of Research - Granthaalayah, Vol. 4, No. 9: SE (2016): 37-49.

\section{INTRODUCTION}

\section{MOTIVATION}

Motivation is a psychological feature that induces an organism to act towards a desired goal and elicits controls, and sustains certain goal-directed behaviors. It can be consider as a driving force, 
a psychological one that compels or reinforces an action toward a desired goal. For example hunger is motivation that elicits a desire to eat. Motivation is the purpose or psychological cause of an action.

Motivation has been shown to have roots in physiological, behavioural, cognitive and social areas. Motivation may be rooted in a basic impulse to optimize well-being, minimize physical pain and minimize pleasure. It can also originate from specific physical needs such as eating, sleeping, or resting and sex.

Motivation is an inner drive to behave or act in a certain manner. "It is the difference between waking up before dawn to pound the pavement and lazing around the house all day". The conditions such as wishes, desires, goals, and other activities move in a particular direction in behavior.

\section{NEED THEORIES}

Motivation, as defined by Pritchard and Ashwood, is the process used to allocate energy to maximize the satisfaction of needs.

\section{MASLOW'S HIERARCHY OF NEEDS}

The American motivation psychologist Abraham H.Maslow developed the hierarchy of needs consisting of seven hierarchic classes. According to Maslow, people are motivated by unsatisfied needs. The needs listed from basic (lowest-earliest) to most complexes (highest-latest) are as follows;

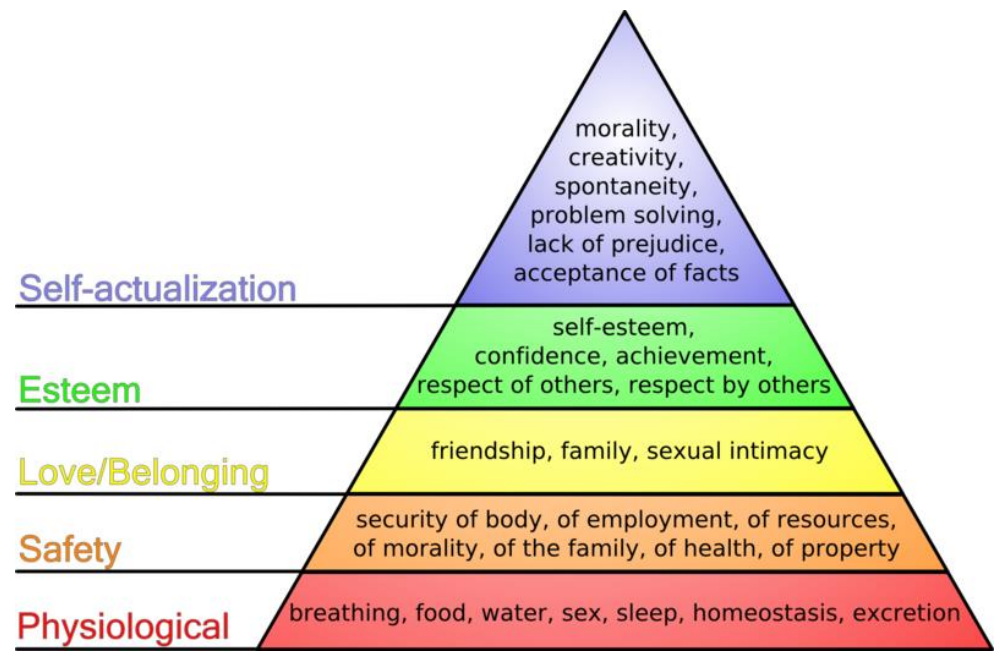

- Physiological: hungry, thirst, bodily comforts sleep etc...

- Safety / Security : out of danger

- Belonging and love: affiliate with others, be accepted

- Esteem: to achieve, be competent, gain approval, and recognition

- Cognitive: to know, to understand and explore

- Aesthetic: symmetry, order, and beauty

- Self-actualization: to find self-fulfillment and realize one's potential 
The basic requirements build upon the first step in the Pyramid: Physiology. If there are deficits on this level, all behaviors will be oriented to satisfy this deficit. Essentially, if one have not slept or eaten adequately, they would not be interested in their self-esteem desires. Subsequently they have the second level, awakens a need for security. After securing those two levels, the motives shift to the social sphere, the third level, which the top of the hierarchy consists of selfrealization and self-actualization

\section{SUMMARY OF MASLOW'S HIERARCHY OF NEEDS}

- Human beings have wants and desires which influence their behavior. Only unsatisfied needs influence behavior, satisfied needs do not.

- Needs are arranged in order of importance to human life, from the basic to the complex.

- The person advances to the next level of need only after the lower level need is satisfied at least to the minimum level.

- The further progress of the hierarchy, the more individuality, humanness and psychological health a person will show.

\section{HERZBERG'S TWO FACTOR THEORY}

Frederick Herzberg's two factor theory, A.K.A Intrinsic/Extrinsic motivation, concludes that certain factors in the workplace result in job satisfaction. But if absent, they do not lead to dissatisfaction but no satisfaction. The factors that motivate people can change over their lifetime but "respect for me as a person" is one of the top motivating factors at any stage of life.

Frederick distinguished between Motivators and Hygiene factors:

- Motivators; (i.e. challenging work, recognition, responsibility) which gives positive satisfaction.

- Hygiene factors; (i.e. status, job satisfaction, salary and fringe benefits) that do not motivate if present, but, if absent, result in demonization. The name Hygiene factors like hygiene, the presence will not improve health, but absence can cause deterioration.

\section{CHARACTERISTICS OF MOTIVATED LEARNERS}

1) If perceived ability is low, extrinsically motivated students are more likely to quit after failure.

2) If the task is mundane or algorithmic, the extrinsically motivated student may be superior to the intrinsically motivated student.

3) If the task is conceptual or requires higher level thinking skills, the intrinsically motivated student is likely to be superior to the extrinsically motivated student.

4) The intrinsically motivated student is more likely to apply effective meta cognitive strategies and "deeper" study strategies.

5) The intrinsically motivated student is more likely to select problems and sub goals of moderate difficulty, whereas the extrinsically motivated student is more likely to select the easiest problems and sub goals.

6) The intrinsically motivated student is more likely to take risks and also to express freely. 
7) If the task is complex, the intrinsically motivated student is more likely to employ logical and efficient performance strategies.

8) Students who have previously been extrinsically motivated to engage in a particular activity are less likely to engage in that activity when external incentives are no longer available.

Intrinsically motivated students are more likely than extrinsically motivated student who are able to handle artificial rewards without experiencing negative consequences.

\section{ACADEMIC MOTIVATION}

A person's desire (as reflected in approach, persistence and level of interest) regarding academic subjects when competence is judged against a standard of performance or excellence. One of the greatest frustrations mentioned by many teachers is that their students are often not able to learn. Teachers quickly come to recognize the warning signs of poor motivation in their classroom. Students put little effort into homework and class work assignments and fail to participate in class discussion. One common method for building motivation is to tie student academic performance and classroom participation to specific rewards or privileges.

\section{DEFINITION OF ACADEMIC MOTIVATION}

According to Pintrich and Zusho, "Academic motivation refers to internal processes that instigate and sustain activities aimed at achieving specific academic goals".

According to Gresham, "Academic motivation is a subtype of the general construct of effective motivation, which is dealing with one's environment".

\section{TYPES OF ACADEMIC MOTIVATION}

Academic motivation is multidimensional in nature and is comprised of two global types of motivation: Intrinsic and Extrinsic motivation.

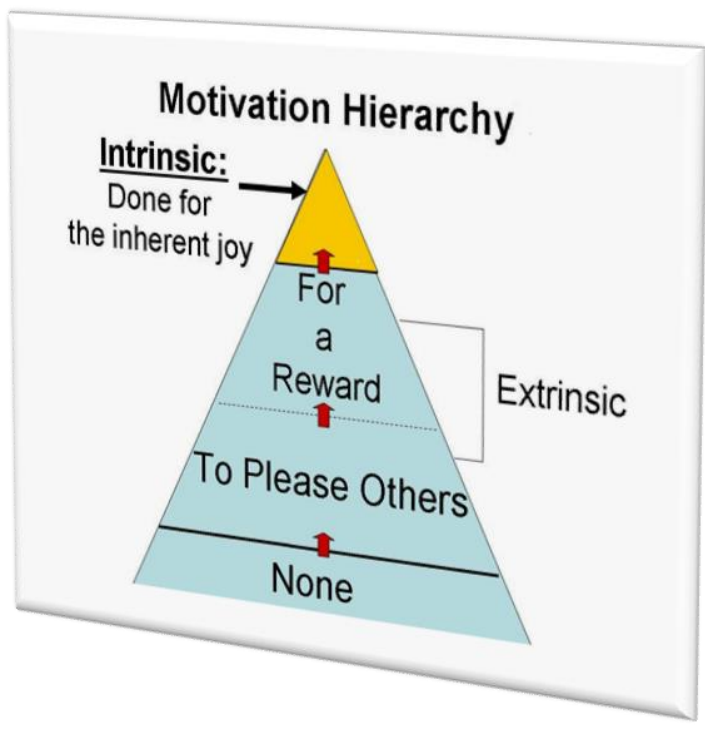




\section{INTRINSIC MOTIVATION}

Intrinsic motivation refers to motivation that is driven by an interest or enjoyment in the task itself, and exists within the individual rather than relying on external pressures or a desire for reward. Intrinsic motivation has been studied since the early 1970s. The phenomenon of intrinsic motivation was acknowledged within experimental studies of animal behavior. In many studies, it was evident that the organism would engage in playful and curiosity driven behaviors in the absence of reward. Intrinsic motivation is a natural motivational tendency and is a critical element in cognitive, social and physical development. Students who are intrinsically motivated are more likely to engage in the task willingly as well as work to improve their skills, which will increase their capabilities.

\section{EXTRINSIC MOTIVATION}

Extrinsic motivation refers to the performance of an activity in order to attain an outcome, whether or not that activity is also intrinsically motivated. Extrinsic motivation comes from outside of the individual.

Common extrinsic motivations are rewards (for example money or grades) for showing the desired behavior and the threat of punishment following misbehaviors. Competition is an extrinsic motivator because it encourages the performer to win and to beat others, not simply to enjoy the intrinsic activity. A cheering crowd and the desire to win a trophy are also extrinsic motivation.

\section{COMPARISION OF INTRINSIC AND EXTRINSIC MOTIVATION}

Social psychological researches have indicated that extrinsic rewards can lead to over justification and a subsequent reduction in intrinsic motivation. In one study demonstrating this effect, children who expected to be rewarded with a ribbon and a gold star for drawing pictures spent less time playing with the drawing materials in subsequent observation than children who were assigned to an unexpected reward condition.

While the provision of extrinsic rewards might reduce the desirability of an activity, the use of extrinsic constraints, such as the threat of punishment, against performing an activity has actually been found to increase one's intrinsic interest in that activity. But when students develop a positive attitude, then it develops an involvement towards the task. They became intrinsically attached to the task. This is permanent and this is a case of intrinsic motivation.

\section{IMPORTANCE OF ACADEMIC MOTIVATION}

- Direct behavior towards particular goals.

- Lead to increase effort and energy.

- Increase initiation of, and persistence in activities.

- Enhance cognitive processing.

- Determine what consequences are reinforcing.

- Lead to improved performance. 


\section{ACADEMIC MOTIVATION IN EDUCATION}

Motivation is of particular interest to educational psychologists because of the crucial role it plays in student learning. However, the specific kind of motivation that is studied in the specialized setting of education differs qualitatively from the more general forms of motivation studied by psychologists in other fields. Motivation in education can have several effects on how students learn and how they behave towards subject matters.

\section{DEVELOPMENT OF ACADEMIC MOTIVATION}

- Children are naturally motivated to learn when they are infants. A baby's struggle to reach a toy, learn to walk without help is an example of motivation to learn.

- This early motivation to learn is later applied to school-related activities such as reading and writing.

- Parents who have standards that are unrealistic can discourage their children's efforts.

- Competition in schools (where someone always wins and someone always loses) can be very discouraging to children, especially those who may never be "the best" at school, even though they can learn a lot.

- Children who do not experience success or whose success is not recognized may develop poor academic motivation.

- Children whose parents or peers do not think school is important or do not place important on doing their best in school also can develop poor academic motivation.

\section{PROMOTING STUDENTS ACADEMIC MOTIVATION}

- Build in rewarding opportunities for social interaction.

- Provide audiences for student work.

- Reduce the effort needed to complete an academic assignment.

- Connect academic requirements to real world situation.

- Offer students meaningful choice wherever possible.

- Make learning fun.

\section{TEACHER'S ROLE IN ACADEMIC MOTIVATION}

- Teacher should give balanced praise and punishment.

- Teacher should give career guidance.

- Teacher should give graded assignments such that everyone will have some success initially and continue their efforts.

- Teacher should give clear cut short term goals.

- Teacher should give immediate feedback to the students, helping each people to develop a realistic level of aspiration.

- Teacher should use of proper incentives as motivating agents, appropriate to the age group of students.

- Teacher should maintain Good rapport with the students inside and outside the class.

- Teacher should give continuous internal assessment. 
- Teacher should emphasize well-structured teaching.

- Teacher should not misguide pupils by stating that failure is the stepping stone for success.

\section{PARENTS ROLE IN ACADEMIC MOTIVATION}

- Parents should be firm and fair when they discipline their child. Children need reasonable discipline to be independent and responsible.

- Parents should teach their child to be responsible at home.

- Parents should maintain a good parent-child relationship.

- Parents should listen to their child talks to them, especially about school.

- Parents should do family activities that encourage learning, such as visit to the library, museums or parks.

- Parents should teach their children that their parent think learning is important and is the central purpose of school.

- Parents should provide opportunities for success.

- Parents should talk with their children about school and shown an interest in their school activities.

- Parents should talk with their children about their career interests and how school is related to a career.

- Parents should praise their children for trying hard and for being successful.

\section{CHARACTERISTICS OF PEOPLE WITH HIGH ACADEMIC MOTIVATION}

- They do well in competitive tasks.

- They generally prefer "skill exercise "to "game of chance".

- They are fast and hard learners.

- They want to live up to a high self-imposed standard of performance.

- They show preference for tasks of middle level probability of success.

- They see problems and obstacles as challenges to be met and are determined to tackle them.

- They show persistence in work at an achievement related task.

- They derive more pleasure from success than those who are weak in achievement motive.

- They have strong desire to excel and beat others or to perform the best.

- They are relatively resistant to outside social pressures.

- They are energetic and generally exhibit a high profile of performance.

\section{ACADEMIC MOTIVATIONAL STRATEGIES IN THE CLASSROOM}

- Teacher should use of proper incentives as motivating agents, appropriate to the age group of students.

- Teacher should help the students to feel the utility of what they learn by relating them to practical life situations.

- Teacher should provide feedback to students about their performance. 
- Teacher should create Goal setting: Motivational behavior is always goal oriented. When the goal is clear and attainable, the students strive hard to reach the goal.

- Teacher should give importance to competition and co-operation: Teachers should stress cooperation as a motive in study and sports.

- Teacher should be Professional competency and sensitivity to the needs of pupils help the teacher in his task and kindle students' interest in their learning.

- Teacher should avoid excessive motivation as it is self-defeating.

- Teacher should develop positive attitude in pupils towards learning itself and proper teacher-pupil relationship is basic to such an attitude.

\section{SELF CONCEPT}

One's self-concept also called self-construction, self-identity or self-perspective. It is a collection of beliefs about oneself that included elements such as academic performance, gender and racial identity.

Generally self-concept embodies the answer to who am I? One's self-concept is made up of selfschemes and their past, present and future selves.

Self -concept is distinguishable from self-awareness which refers to the extent to which selfknowledge is defined, consistent and currently applicable to one's attitudes and disposition. Selfconcept is a cognitive or descriptive component of one's self.

\section{MEANING OF SELF-CONCEPT}

Self-concept is the feelings which one has about oneself and such as self-evaluation greatly influences his behaviors, colors interpretation of environmental situations and interferes with one's judgements.

The child's self-concept develops gradually through his own actions, in the family, the school, peer groups and the society at large. The society in which he lives serves as mirror, reflecting his self-image and self-worth.

Heredity factors also influence the family and external social environment as the important determinants of self-concept.

\section{FEATURES OF SELF-CONCEPT}

Self-concept has past self, presents self, future possible selves and self-schemes.

For example: I am a fast runner. 


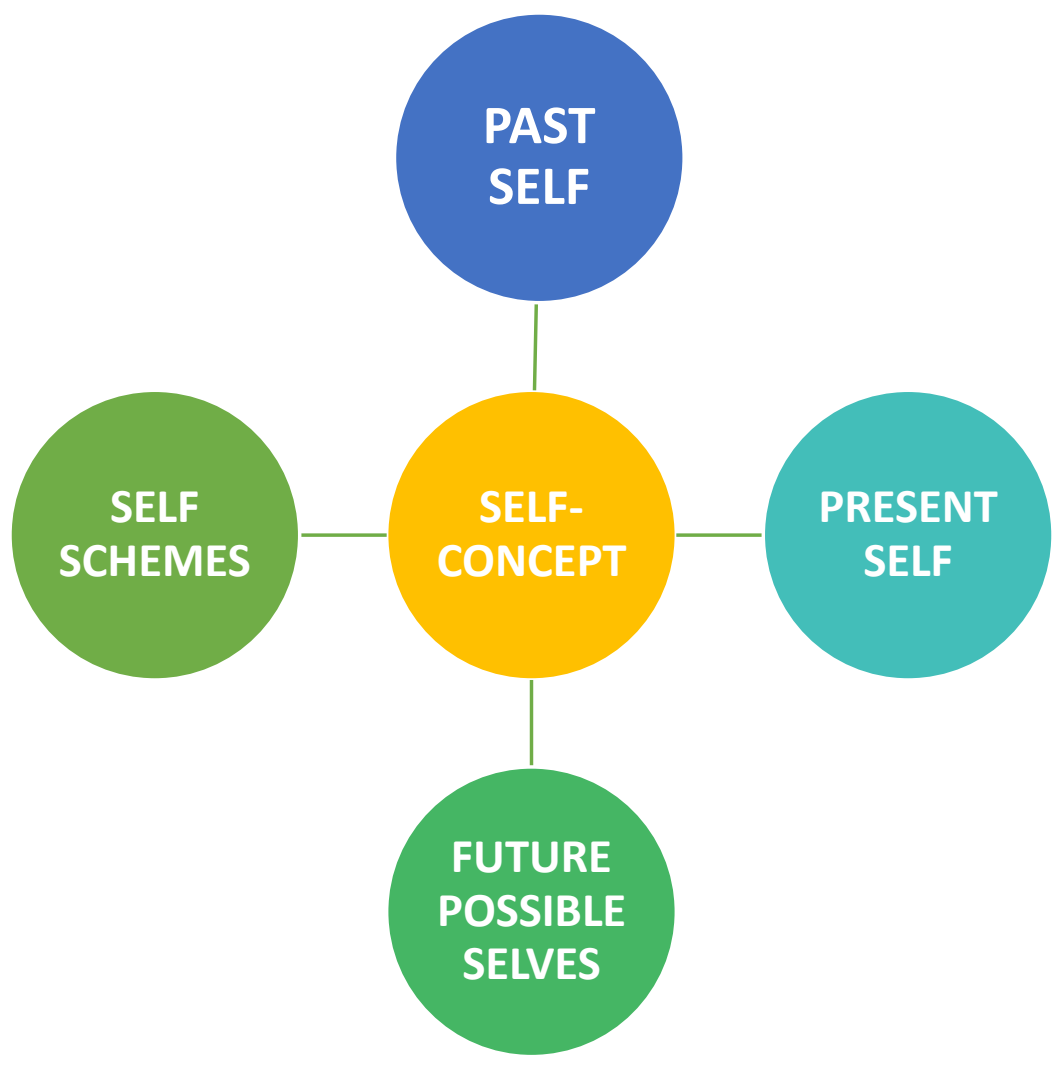

\section{ACADEMIC SELF-CONCEPT}

Academic self-concept refers to the personal beliefs about their academic abilities or skills. Some research suggests that it begins developing from age 3 to 5 from the influence of parents and early educators.

By age 10 or 11, children assess their academic abilities by comparing themselves to their peers. These social comparisons are also referred to as self-estimates. Self-estimates of cognitive ability is most likely to be poor in other areas, such as reasoning speed.

\section{DEFINITION OF ACADEMIC SELF-CONCEPT}

According to Bracken "Academic self-concept is how a person feels about himself / herself within a school or academic setting or in relation to a student's academic progress. Academic self-concept is hierarchical organized and multifaceted in nature."

According to Wig Field "Academic self-concept refers to individuals' knowledge and perceptions about themselves in academic achievement situations".

\section{TYPES OF ACADEMIC SELF-CONCEPT}

One of the most important distinction of academic self-concept is that between global and domain specific self-concept.

1) Global Domain Self-concept

2) Specific Domain Self-concept 
Types of Academic Self-Concept

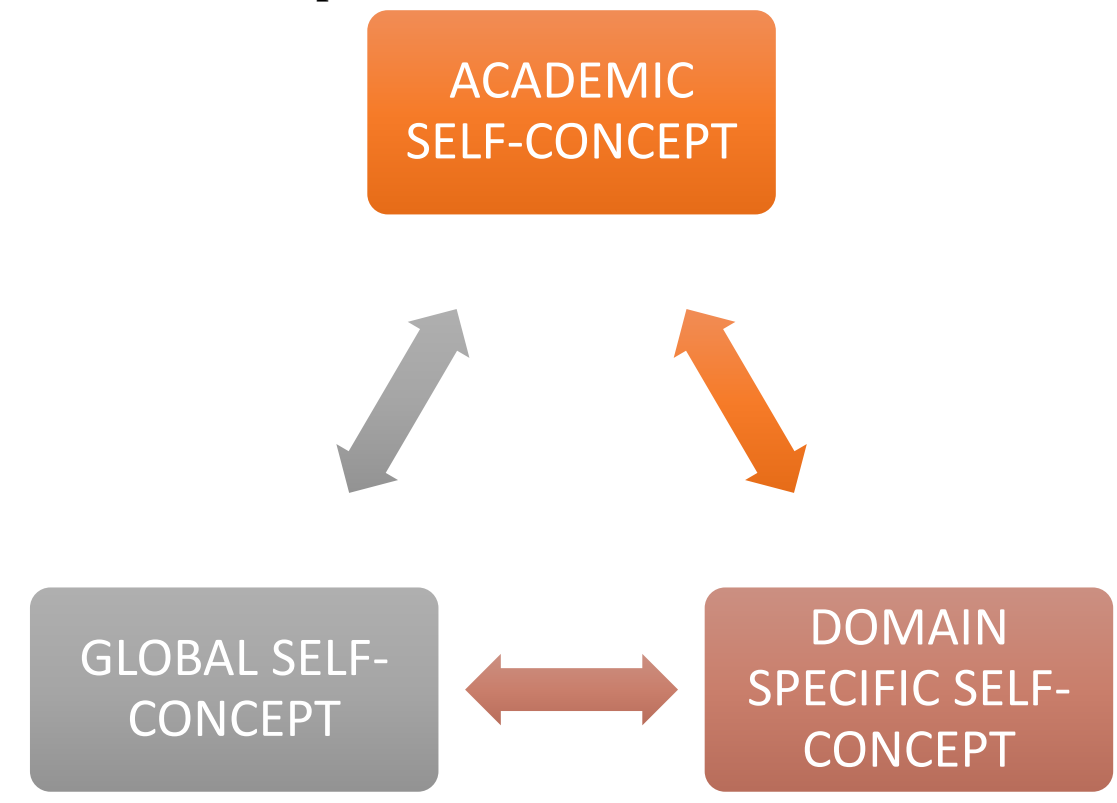

\section{GLOBAL AND DOMAIN SPECIFIC SELF-CONCEPT}

Academic self-concept globally is a student's perception of his or her general ability in school. However, many researchers have argued that academic self-concept is multidimensional and varies across school subjects. i.e.Math self-concept (students belief that they can do well in mathematics) .Literacy self-concept (students belief that they can do well in reading or language arts).

To understand the relationship between academic self-concept and academic achievement outcomes, it is necessary to recognize that general and domain- specific self-concept may be different.

\section{DEVELOPMENT OF ACADEMIC SELF-CONCEPT}

- Most of the research suggests that to raise academic self-concept, parents and teachers need to provide children with specific feedback that focuses on their particular skills or abilities.

- Learning opportunities should be conducted in groups (both mixed ability and like ability) that downplay social comparisons.

- Teacher should give positive self-concept that attempts to be creative, original, spontaneous and generous.

- Teacher should motivate higher level of aspiration and improved academic self-concept.

- School and classroom environment are important factors of academic self-concept.

RELATIONSHIP BETWEEN ACADEMIC SELF-CONCEPT AND ACHIEVEMENT 
- Increase in academic self-concept lead to increase in subsequent academic achievement and other desirable educational outcomes.

- Self-concept is an important outcomes variable in itself, it also plays a central role in mediating the effects of other desirable educational outcomes.

- Academic self-concept is formed and developed through interactions.

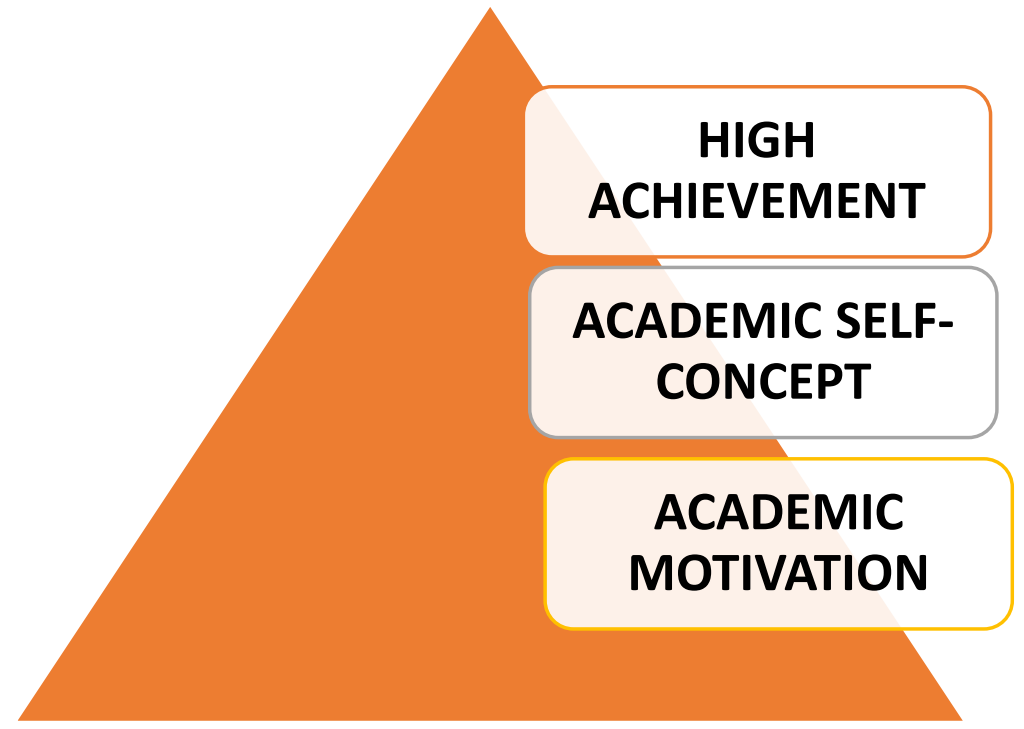

\section{NEED OF ACADEMIC MOTIVATION AND ACADEMIC SELF-CONCEPT}

A large number of personality characteristics are related to motivation and academic selfconcept. For example, Atkinson (1964) has classified people are motivated either by

- seeking success or

- Avoiding failure.

1) It is acceptable that success seekers increase motivation for success; but failure avoiders decrease their efforts after failing at a task. In addition, success seekers seem to be most strongly motivated by tasks that have a medium level of difficulty, whereas failure avoiders seem to prefer either very easy or very difficult tasks.

2) Finally, success seekers are more likely to set realistic goals, whereas failure avoiders tend to set goals for themselves that are unrealistically easy or difficult.

3) Teachers often use the term self-motivated to refer to students who become easily motivated to learn, without much external persuasion .It leads to a strongest form of motivation.

4) Self-motivated learners are likely to be the best learners, if their motivation is directed towards productive goals. Self-motivation is not an innate characteristic, but rather is learned in much the same fashion as the Meta cognitive skills.

5) Teachers should be aware that by enabling learners to employ motivational strategies effectively .They can help the students to develop the personality trait of self-motivation. It can be helpful for both academic and non-academic tasks. 
- Fear of failure,

- Lack of challenge,

- Lack of meaning,

- Emotional problems,

- Anger,

- Desire for attention.

\section{ROLE OF REWARDS AND PUNISHMENTS IN ACADEMIC ACHIEVEMENT}

Rewards and punishment are the two potent and powerful incentives which influence the future conduct or learning of an organism. Roll of honour, prizes, badges and the like are various forms of rewards. Rewards help to stamp in the desired responses. Punishment is supported to stamp out the SR connection as suggested by Thorndike(law of effect).

\section{ADVANTAGES OF REWARDS}

- Rewards serve as positive reinforces. As they are associated with success, they generate joy and satisfaction in the minds of the learners.

- Rewards lead to social recognition, which in turn promotes opportunities to express the initiative, creativity etc. of pupil.

- Rewards appeal to ego maximization and develop high morale.

- Rewards enhance the efficiency of the talented.

\section{LIMITATIONS OF REWARDS}

- Rewards will not motivate all but some who are almost equal in their efficiency.

- As rewards are extrinsic, they may not promote intrinsic interest in learning.

- Rewards tempt the learner to get them by any means including cheating.

- Rewards create unhealthy competition among the students.

\section{ADVANTAGES OF PUNISHMENT}

- Punishment act as deterrent of wrong behaviour.

- Simple punishments serve as a form of discipline in the class.

- Punishment immediately corrects the wrong doer and warns others not to repeat the same mistake.

- Punishment will be effective only when they are administered impartially.

\section{DISADVANTAGES OF PUNISHMENT}

- Punishment is based on fear and they are less effective.

- They create unpleasant feelings and naturally associated with failures.

- The results of punishment are not always permanent. 
- They loss their effectiveness, if the pupil is either not afraid of them or willing to accept them.

- They create ill feelings among the teachers and students.

- Sometimes those who are punished may appear to be heroes to others.

- Some punishments shatter the self-confidence of emotional persons.

\section{PARENTS ROLE IN STUDENT'S BEST OUTCOME}

- Provide a warm, accepting home environment.

- Give clear directions and feedback.

- Create a model for success

- Build on the student's strengths

- Relate schoolwork to the student's interests

- Help build a family structure that fosters consistent work towards the goal.

- Help the student to have some control over how and when he learns.

- Emphasize the child's progress rather than his or her performance in comparison to the other students in the class or family.

- Remember to reinforce the behavior you want.

\section{CONCLUSION}

Today Academic Motivation and Academic Self-concept play a vital role in achieving the goals. Students need to establish and maintain a positive learning environment for attaining success. Students are not sufficiently trained to deal with today's behavioral problems of life. It is a need of the hour for the teachers to learn the effective strategies for enhancing the students' Academic Achievement. "The quality of the relationships that students have in class with their peers and teachers is important to their success in school." -Bob Pletka. Teacher's special attention and care serve as a stimulating force in restoring back the natural Achievement level in pupils.

\section{REFERENCES}

[1] Archana, K, \& Chamundeswari, S.(2013). "Self-Concept and Academic Achievement of Students at the High School”. Journal of Sociological Research. Vol.4 pp. 105 -113.

[2] Bachman J. G. \& O’ Mally P. M. (1986). Self-concept, Self-esteem and Educational Experiences: Journal of Personal and Social Psychology; 50, 1, 35-46

[3] Biehler, R. F. and Snowmnan, J. (1986). Psychology Applied to Teaching. (5th Ed.) Boston: Houghton Mifflin Company.

[4] Brown S, Armstrong S, Thompson I 1998. Motivating Students. London: Kogan Page Limited.

[5] Fontana, D. (1981). Psychology for Teachers. London: Macmillan Press Ltd.

[6] Golden, S. A. R. (2011). Problems and Prospectus of Distance Learning. Bharathidhasan University, 343, 344.

[7] Golden, S. A. R. (2011). Strategy For Success Of Human Beings:-Time Management. 